\title{
A ECONOMIA DE FRANCISCO E CLARA: UM PLANO PARA REALMAR A SOCIEDADE
}

Eduardo Brasileiro ${ }^{1}$

\section{Resumo}

A Economia de Francisco e Clara, convite feito pelo Papa Francisco à sociedade global é uma possibilidade de revisitar a análise da economia política, escanteada pelo principal ator da economia global, o mercado financeiro. Intencionalmente A Economia de Francisco e Clara é apresentada como um pacto, reconhecendo que novos rumos para a economia se darão a partir de movimentações para além da própria ciência econômica. Envolvendo a conjugação de formulações políticoeconômicas populares e também as instituições dedicadas aos movimentos populares. O texto é um convite para enfrentar a ortodoxia capitalista e reinventar outros imaginários possíveis a partir do paradigma da vida para todos e não da cultura do descarte.

Palavras-Chave: Economia. Papa Francisco. Capitalismo. Neoliberalismo.

\section{$O$ capitalismo é para poucos}

O século $X X$ foi um ensaio da beleza e do horror construído no segundo milênio. Nele a economia de latifúndio escravagista tomou corpo na industrialização e no desenvolvimentismo, a sede de progresso tecnológico foi entremeada por guerras, massacres e conflitos de ontem e de hoje. Todos escreveram novas formas de colonialismos e de aprofundamento do capitalismo, ambos, portanto, são corpo e forma da economia do presente. Também neste breve século - se formos pensar somente na vida -, foi possível alcançar a arte na profundidade da alma humana, século das novas formas de organização e de luta, de conquistas e da marca da resistência como perenidade do ser humano em sua busca pela liberdade. Tempo das lutas pela erradicação da fome, da educação

\footnotetext{
1 Sociólogo pela FESPSP (Fundação Escola de Sociologia e Política de São Paulo) é diretor do Instituto Cultiva e membro da Articulação Brasileira pela Economia de Francisco e Clara. É jovem selecionado para o evento global com o Papa Francisco "Economia de Francisco" a partir do trabalho como educador que executa junto às Comunidades Eclesiais de Base nas periferias de São Paulo.
} 
como prática de liberdade, da política como bem comum, tempo das redes de resistência de comunicação livre.

O ser humano também passa por uma transição. Do agrarismo do final do século XIX para o industrialismo do século $X X$, para enfim a era do trabalho imaterial. O capitalismo neste último período financeirizou-se (DOWBOR, 2017) e isso acarretou uma concentração de renda nunca vista na história, somada a uma destruição do trabalho na sociedade de classes. No mundo o processo de destruição da seguridade social e de todas as políticas sociais está mais agressivamente presente no advento do neoliberalismo, essa doutrina econômica que constrói o sujeito empresarial. Este que é apenas comunitário para a construção de relações (network) bem presente nas comunidades de fé neopentecostais. O 'patrão de si mesmo' é um modo de vida do imperialismo às avessas, propondo que você seja uma empresa, dê lucro, produtiva e tenha suas finanças, em meio ao abandono de qualquer política de proteção que o Estado haveria dado no século passado.

O desafio para este tempo do mundo reside numa nova subjetividade, onde espiritualidade libertadora e pluralista somada a contra-condutas diante do império neoliberal reposicionem um novo ser e estar no mundo. O Papa Francisco, se não atento a isso, pelo menos atento aos protagonistas da história, os pobres, conectou aos movimentos populares uma nova ação eclesial engajada: Laudato Si' - Sobre o Cuidado da Casa Comum e Frateli Tutti - Sobre a Fraternidade e a Amizade Social, são cartas que anunciam esse limiar. A reconstrução de uma ecologia integral e uma fraternidade universal, ambas apontam a retomada do ser ecológico do humano e da economia como mote de solidariedade e nova cultura de relações, não mais líquidas e descartáveis, mas territoriais e fraternas.

A Economia de Francisco e Clara é uma ferramenta desse instrumento revolucionário: novas narrativas e inserções territoriais. No Brasil, o chamado do Papa Francisco para a Economia de Francisco foi feito uma inclusão contestatória: Clara. Os povos a saber, movimentos populares, organizações da sociedade civil, professores/as, juventudes e ativistas, entendem esse chamado a olhar para a cidade de Assis, onde jovens puderam construir um ideal de vida de solidariedade e ecologia 
integral, como chave emancipatória: uma oportunidade de construir outros mundos. E, sabe-se que haverá nova sociedade a partir das vozes silenciadas por esse atual sistema, em especial, as mulheres.

A Economia de Francisco, convite feito pelo Papa Francisco à sociedade pluralista, traz no bojo de sua iniciativa a abertura de processos revolucionários, pois incide em

"[...] ocupar-se mais com iniciar processos do que possuir espaços. O tempo ordena os espaços, ilumina-os e transformaos em elos de uma cadeia em constante crescimento, sem marcha atrás" (FRANCISCO, 2013c, n.223). Francisco, assume que "não há duas crises separadas: uma ambiental e outra social; mas uma única e complexa crise socioambiental" (FRANCISCO, 2015b, n. 139).

Deste modo, surge do Papa "vindo do fim do mundo" um pacto para construir economias que sejam desses lugares silenciados pela hegemonia capitalista, a partir dos lugares das juventudes das periferias que ele convoca e que trazem experiências particulares. A convicção que carregam é unânime: o capitalismo é para poucos, eis a chance de mudar de caminho.

\section{Por que a economia no centro do debate de uma nova sociedade?}

O sistema econômico capitalista em sua contemporaneidade é visto por dois prismas. O primeiro é de seu esgotamento e sua possibilidade de metamorfose, e que, portanto, o velho sistema tem uma capacidade de recuperar sua natureza inquieta e criativa para chamar a si um protagonismo no mundo de hoje. Uma segunda hipótese, é de uma simples continuidade, e que o motor do capitalismo seja por si mesmo susceptível a crises que o embalam na governança do mundo. Em ambas as hipóteses se reconhece que "[...] A plasticidade do capitalismo permite que ele assuma o espírito do tempo e, com isso, vá se transmutando e se tornando senhor do tempo e do espaço" (BELLUZZO, 2020)

O Papa Francisco em seu documento gênese da discussão econômica, a Encíclica Laudato Si', afirma que no sistema econômico atual "(...) há um modo desordenado de conceber a vida e a ação do ser humano, que contradiz a realidade" (FRANCISCO, 2015b, n. 101) apontando que a raiz da crise ecológica e econômica é humana a partir do paradigma tecnocrático dominante: o capitalismo financeiro. Uma 
arquitetura econômica onde as aplicações financeiras têm rendido entre $7 \%$ a $9 \%$ enquanto o PIB global cresce na ordem de $2 \%$ a $2,5 \%$ (DOWBOR, 2020. P: 62).

Afinal, a economia deu rumo no último século às escolhas globais do período pós-guerra. Celso Furtado (1973, p. 14) afirmará que o padrão das ciências econômicas a partir das narrativas políticas de esquerda ou de direita na década de 60 e 70 se baseavam num mito em que o bom da vida é aumentar o consumo e que o padrão de consumo poderia ser universalizado. A boa vida se dá no presente e não no pós morte, através de progresso científico-tecnológico e a partir da planificação do consumo. se sentido, a formulação política da esquerda criticará que o mercado não pode se autorregular livremente e a direita também dirá que a planificação estatal é perigosa pois nega a liberdade econômica.

O mito do desenvolvimento econômico deu origem, portanto, a um capitalismo da grande indústria, da finança e da construção do espaço global, entre crises e recuperações, de transformar e dominar a natureza, até mesmo podendo reinventá-la. É nesse sentido que o Papa Francisco, afirmará que o crescimento tecnológico não foi acompanhado de desenvolvimento da vida do planeta (FRANCISCO, 2015b, n. 105), a partir do paradigma do desenvolvimento integral, que não concebe crescimento infinito num planeta com recursos finitos.

A despeito disso, foram assim implantadas as reformas liberalizantes no Estado e o tornou um facilitador das elites financeiras (CASTELLS, 2018. P.96). Mero gestor da vida dos mercados, é fruto de uma dimensão que reduziu os investimentos públicos - portanto, comuns - e maximizou o descontrole de legislações, como é o exemplo do Brasil, na lei no 9249 de 26 de dezembro de 1995, que isentou taxação sobre lucros e dividendos das grandes fortunas.

Os caminhos econômicos, portanto, estão no centro do debate sobre as desigualdades, na refundação de uma ética ecológica (BOFF, 1999) e no firmamento da construção do homem moderno. Em Eros e Civilização, Herbert Marcuse, sociólogo alemão, apresentou argumentos em que a produção e o consumo reproduzem e justificam a dominação. Portanto, a cultura material terá mais valor que o seu tempo livre, sua consciência e seus sonhos nunca realizados. O Papa Francisco 
sintetizará essa discussão numa chave humanística, que ele apresenta em seu mais recente documento, Fratelli Tutti - sobre a amizade social:

O mundo moderno, devido à sua perfeição técnica, tende a racionalizar cada vez mais a satisfação dos desejos humanos, classificados e distribuídos entre vários serviços. Um homem é chamado cada vez menos pelo seu próprio nome, cada vez menos será tratado como pessoa este ser, único no mundo, que tem o seu próprio coração, os seus sofrimentos, problemas e alegrias e a sua própria família. Só se conhecerão as suas doenças para tratá-las, a sua falta de dinheiro para fornecê-lo, a sua necessidade de casa para alojá-lo, o seu desejo de lazer e de distrações para os organizar. (FRANCISCO, 2020a, n. 193).

Para isso, a Economia de Francisco e Clara é um deslocamento da estrutura de interpretação da realidade econômica centrada no dinheiro para a vida humana e não humana. As soluções passam pela superação do discurso de mercado hegemônico que atua pela racionalidade neoliberal, que produz ao invés de homens e mulheres sensíveis à realidade, apenas sujeitos empresariais. (DARDOT; LAVAL, 2016, p. 396).

\section{Realmar a economia}

O pacto social proposto pela Economia de Francisco e Clara está em reconectar pessoas à pensamentos e práticas, "[...] O que penso, sinto e faço, o que sinto, penso e faço, o que faço, penso e sinto" ${ }^{2}$. O Papa Francisco é pragmático e vê as principais ferramentas de mudanças nos empobrecidos a partir dos movimentos populares.

Os últimos, em geral,

«praticam aquela solidariedade tão especial que existe entre quantos sofrem, entre os pobres, e que a nossa civilização parece ter esquecido, ou pelo menos tem grande vontade de esquecer. (...) é pensar e agir em termos de comunidade, de prioridade da vida de todos sobre a apropriação dos bens por

2 Para saber mais da Pedagogia do Papa Francisco: "Scholas Ocurrentes: Projeto político pedagógico de Francisco que atualiza as CEB's em: http://www.ihu.unisinos.br/78noticias/579478-scholas-ocurrentes-projeto-politico-pedagogico-de-francisco-queatualiza-as-cebs. Último acesso em 01/04/2021. 
parte de alguns. É também lutar contra as causas estruturais da pobreza, a desigualdade, a falta de trabalho, a terra e a casa, a negação dos direitos sociais e laborais. É fazer face aos efeitos destrutivos do império do dinheiro (...). A solidariedade, entendida no seu sentido mais profundo, é uma forma de fazer história e é isto que os movimentos populares fazem». (FRANCISCO, 2020a, n. 116)

É sintomático que o documento principal do pontificado de Francisco, coloque os pobres como sujeitos de mudança. Não se trata de romper com a credibilidade dos tratados internacionais expressos na COP 21 ou nos 17 ODS (Objetivos para o Desenvolvimento Sustentável) e a conscientização dos atores globais. É expressar as raízes da teologia latino-americana que coloca no centro a busca pela libertação dos oprimidos a partir de novas formulações políticas, econômicas e culturais. Trata-se de horizontalizar as lutas pelos direitos da natureza e dos empobrecidos, articulando-as num só grito por novas economias. Por isso, a escolha de Francisco e Clara de Assis, santos que souberam imprimir na vida a espiritualidade que se alastra pelas correntes sanguíneas e transborda na voz, no diálogo, no encontro.

Há nesse sentido imperativos que se forjam no seio da agenda da Economia de Francisco e Clara: a correção dos modelos de crescimento, modelos de trabalho, modelos de sociabilidade e modelos de distribuição. Vamos aos pontos.

O modelo de crescimento atual se resume em concentração de riquezas e espoliação econômica dos grandes mercados, suprimindo toda competição. É a subutilização do capital, que se transforma em patrimônio familiar e aplicações financeiras em vez de investimentos produtivos. Isso trava o desenvolvimento de infraestruturas, a produção de bens e serviços e o emprego. Os 206 bilionários brasileiros apresentados na edição especial da Fortune são essencialmente donos de holdings, acionistas, controladores de fundos de investimentos, donos de cotas acionárias, e naturalmente banqueiros ou acionistas de bancos.

A necessidade de correção dos modelos de trabalho é óbvia no Brasil de 2020. Neste país de 212 milhões de habitantes, o emprego formal privado se resume a 33 milhões de pessoas. Somando-se os 11 milhões de funcionários públicos, chega-se a 44 milhões, que é apenas $42 \%$ da força de trabalho de 105 milhões. A subutilização da força de 
trabalho constitui uma dimensão particularmente gritante da fragilidade econômica brasileira, pois se trata, para além do drama social, de uma enorme insensatez econômica (DOWBOR, 2020. P: 69).

O filósofo Byung Chul Han (2017, 23), ao dissecar a sociedade do hiperconsumo, demonstra que o advento do neoliberalismo trouxe a transição da sociedade disciplinar para a sociedade do desempenho. Trata-se de uma chave de inversão do papel da sociedade do trabalho e da sociabilidade pós-moderna. Remete todos à experiência do esgotamento a lógica de sociabilidade que escanteia a capacidade de "educar para a cultura do discernimento, da proximidade e da solidariedade" (SAYAGO. p. 37).

Presente em todas as comunidades, ainda que silenciadas, resiste a cultura solidária. A economia solidária espalhada em diversas redes por toda a América Latina não permite que o neoliberalismo roube a comunidade (FRANCISCO, 2013c, n. 92). Corrige o modelo de distribuição pois tem tecnologias que trazem a solidariedade e a educação popular para dialogar. As moedas sociais e os Bancos de Desenvolvimento Territorial, por exemplo, são um processo de transição, o que nas palavras de Jurgen Schuldt (apud ACOSTA, 2015, p. 164), a "dissociação seletiva e temporal do mercado mundial", retomando a soberania alimentar, processos de gestão democrática local e popularização do binômio formação de redes comunitárias e ocupação de espaços representativos deliberativos.

\section{Ecologia, economia e espiritualidade integral}

A contribuição da Economia de Francisco e Clara é um marco para a transição de um mundo que não é visto apenas em conceitos parciais. Por isso propõe superar a visão da ecologia entendida apenas como delimitação do meio ambiente, da espiritualidade como restrita ao monopólio religioso e da economia como reduzida à relação de mercado.

O homem e a mulher contemporâneos seguem a difícil missão de superar o dualismo que forjou a época moderna. Homens e mulheres são sistemas econômicos, e assim sendo, precisam reconhecer que forjar uma economia para todos é uma condição humana. A espiritualidade, deve imprimir o sentido social da existência, portanto a dimensão fraterna 
da espiritualidade (FRANCISCO, 2020a, n.86). Essas formulações são imprescindíveis para superar o neopentecostalismo que imprime a gramática neoliberal nas classes populares.

Realmar a economia, portanto, imprime práticas territoriais que coloquem no chão das comunidades o reconhecimento da ecologia integral, porque os "(...) ambientes onde vivemos influem sobre a nossa maneira de ver a vida, sentir e agir" (FRANCISCO, 2015b, n. 147). Rezar e partilhar o pouco que se tem é insistir no comum e fazer a comunidade. A experiência da Economia de Francisco e Clara é um movimento social que vai ao coração da dominação ocorrida nas pessoas e as provoca a serem sinal da vida.

O chamado a espiritualidade integral passa pela desconstrução do caminho de dominação e pelo esforço da cultura do encontro:

fazer crescer uma cultura do encontro que supere as dialéticas que colocam um contra o outro. É um estilo de vida que tende a formar aquele poliedro que tem muitas faces, muitos lados, mas todos compõem uma unidade rica de matizes, porque "O todo é superior à parte».[205] O poliedro representa uma sociedade onde as diferenças convivem integrando-se, enriquecendo-se e iluminando-se reciprocamente, embora isso envolva discussões e desconfianças. Na realidade, de todos se pode aprender alguma coisa, ninguém é inútil, ninguém é supérfluo. Isto implica incluir as periferias. Quem vive nelas tem outro ponto de vista, vê aspetos da realidade que não se descobrem a partir dos centros de poder onde se tomam as decisões mais determinantes. (FRANCISCO, 2020aㅡ, n. 215)

Desse modo surgem iniciativas diversas nos países onde jovens, ativistas, pesquisadores e demais interessados compõem a Economia de Francisco e Clara como um elo para reaprender a viver no mundo na tarefa de convergir, em múltiplos espaços juvenis e formativos, esta raiz metodológica do pontificado do Papa Francisco: a cultura do encontro. Um exemplo, são as Casas de Francisco e Clara que possuem um chamado a todas as pessoas, especialmente às juventudes, de experienciar ecologias e economias de maneira integral. As juventudes são convidadas a perceber nas brechas da economia real, as fissuras do mercado, que segue descartando pessoas e, através do encontro com os empobrecidos resgatar elementos reais para reconstruir novas interações ecológicas e econômicas, a partir de outras lógicas, dialógicas e inclusivas, por outras economias, criativas, populares e solidárias. 
A fronteira atravessada pelo movimento social da economia de Francisco e Clara é o encontro com o pensamento crítico, com as possibilidades aventadas pelas ciências econômicas que não se curvam à doutrina de mercado. O Papa Francisco sugere para superar a fragmentação social que "toda a mudança precisa duma caminhada educativa que envolva a todos" e, para tanto, sugere a construção de uma "aldeia da educação", na qual, na diversidade, partilhe-se o compromisso de gerar uma rede de relações humanas e abertas (FRANCISCO, 2019a, $\mathrm{s} / \mathrm{p})$.

Como observou Thomas Piketty, "toda a história dos regimes desiguais mostra que são sobretudo as mobilizações sociais e políticas e as experimentações concretas que permitem mudar a história (PIKETTY, p.1112). Portanto, a intersecção entre povos, seus saberes e de agendas políticas, podem resgatar um processo fundamental da construção de consciência histórica: "A experiência histórica continua sendo a nossa principal fonte de conhecimento" (PIKETTY, p 947). Ou seja, temos os recursos financeiros e tecnológicos para assegurar a conversão para uma nova sociedade, mas não temos poder político sobre as corporações e nem formulação política sobre as pessoas. O enfrentamento ao monopólio capitalista ganha uma importante oposição com o movimento Economia de Francisco e Clara que se coloca ao lado da conversão para outros mundos possíveis.

\section{Bibliografia}

ACOSTA, Alberto. O Bem Viver: uma oportunidade para imaginar outros mundos. São Paulo: Autonomia Literária, 2016.

ARTICULAÇÃO BRASILEIRA PELA ECONOMIA DE FRANCISCO E CLARA. Carta de Clara e Francisco. Direto do Brasil para o Encontro

Mundial em Assis. Instituto Humanitas Unisinos, 30 nov. 2019. Disponível em: http://www.ihu.unisinos.br/78-noticias/594766-carta-declara-e-francisco-direto-do-brasil-para-o-encontro-mundial-em-assis.

Acesso em: 19 dez. 2019

CASTELLS, Manuel. Ruptura: a crise da democracia liberal. São Paulo: Zahar, 2018. 
CORTINA, Adela. Aporofobia a aversão ao pobre: um desafio para a democracia. São Paulo: Contracorrente, 2020.

DARDOT, Pierre; LAVAL, Christian. A nova razão do mundo: ensaio sobre a sociedade neoliberal. São Paulo: Boitempo, 2016.

DOWBOR, Ladislau. 0 capitalismo se desloca. São Paulo: edições Sesc, 2020.

FRANCISCO, Papa. Exortação Apostólica Evangeli Gaudium: o anúncio do Evangelho no mundo atual. Roma, 24 nov. 2013c. Disponível em: http:// www.vatican.va/content/francesco/pt/apost_exhortations/documents/pap a- -francesco_esortazione-ap_20131124_evangelii-gaudium.html. Acesso em: 12 dez. 2020.

FRANCISCO, Papa. Laudato Si': sobre o cuidado da Casa Comum. Roma, 24 maio 2015b. Disponível em: http://w2.vatican.va/content/francesco/pt/encyclicals/documents/papafrancesco_20150524_enciclica-laudato-si.html. Acesso em: 7 dez. 2020. FURTADO, Celso. Teoria e Política do Desenvolvimento Econômico. São Paulo: Abril Cultural, 1973.

HAN, Byung Chul. Sociedade do Cansaço. Petrópolis: Vozes. 2015.

PIKETTY, Thomas. O capital no século XXI. Rio de Janeiro: Intrínseca. 2013.

PIKETTY, Thomas. Capital et idéologie. Paris: Éditions su Seuil, 2020. SAYAGO, Óscar Armando Perez (org.). O projeto educativo de Francisco. Curitiba: Pucpress, 2019 